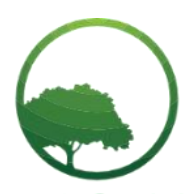

Research in Business \& Social Science

\title{
Investigating the effect of organizational culture on strategy implementation process of private chartered universities in Kenya
}

\author{
Joyce Wanjiku Nderitu@(a), Esther Waiganjo(b), George O. Orwa(c) \\ (a,b,c) Jomo Kenyatta University of Agriculture and Technology, Kenya
}

Crossref

\begin{tabular}{l} 
A R T I C L E I N F O \\
\hline Article history: \\
Received 07 April 20 \\
Received in revised form 22 April 20 \\
Accepted 24 April 20 \\
\hline Keywords: \\
organizational culture, clan culture, \\
strategy, implementation, strategy \\
implementation \\
JEL Classification: \\
M1, M14
\end{tabular}

\begin{abstract}
A B S T R A C T
This study aimed at investigating the effect of organizational culture and strategy implementation process of Private chartered universities in Kenya. The cross-sectional survey research design was adopted and it used both quantitative and qualitative data as it seeks the effect of organizational culture on the implementation of corporate strategy. The accessible population included Registrars, Deans, Directors, Heads of Departments, academic staff, and students' leaders. This study used both stratified random sampling and the target sample size was 198 employees. The statistical package for social sciences (SPSS) version 21 was used to analyze data. The competing values framework was adopted to identify the organizational culture types that are displayed in Private chartered universities. A multiple linear regression model was also used to derive inferential statistical indicators. Normality testing was done to compare the cumulative distribution of the data with the expected cumulative normal distribution and it bases its $P$ value on the largest discrepancy. Two versions of Breusch-Pagan tests were conducted to test the null hypothesis on whether heteroscedasticity or homoscedasticity was present. Based on the regression analysis it was clear that the null hypothesis was rejected and the alternative hypothesis accepted. The conclusion was that Clan culture had a significant influence on the strategy implementation process of Private chartered universities in Kenya. The results established that there was a linear positive relationship between Clan culture and strategy implementation which implies that an increase in Clan culture would lead to a linear increase in Strategy implementation in Private chartered universities in Kenya. (C) 2020 by the authors. Licensee SSBFNET, Istanbul, Turkey. This article is an open access article distributed under the terms and conditions of the Creative Commons Attribution (CC BY) license (http://creativecommons.org/licenses/by/4.0/).
\end{abstract}

\section{Introduction}

Organizational culture is an important element of effective management practices in higher education institutions. In the past, researchers have studied on the organizational concept in order to provide effective managerial in the universities (Beytekin, et al., 2010). The rigorous frameworks of strategy formulation are giving place to flexible and dynamic frameworks of strategy implementation that can take today's organizations to a new ways of thinking and action (Kumar, 2015). On the other hand, success in corporate management of an organization and its efficiency calls for creating and accomplishing the new concepts of corporate strategy which are focused on the processes of corporate strategy and its implementation. This gives the best probabilities for creating corporate and competitive advantage (Sekulić, 2002). As a result of this, there has been high demand of new forms of managerial thinking, organizational cultures, global mindsets, considerable strategic and structural flexibility, and innovative methods for implementing strategies in the business frontier are in dire need (Schaap, 2006).

Universities need the right kind of organizational culture which is a key element of strategy implementation process implementation process (Rajasekar, 2014). Studies have been done on the subject of organizational culture and the influence it has on other organizational variables especially in the 1980s. As a result of these studies, the subject has become popular among the managers who have understood that organizational culture could affect organizations and implementation of their strategies (Lund, 2003). Organizational culture and strategy are two important factors that contribute to the growth of an organization and the continuation of its business; and for this to take place, it is important to consider the organizational culture that aids the process of strategy implementation (Nawasar, et al, 2014). Nawasar, et al (2014) has further noted that there is a gap between implementation of generic competitive strategies and the organization's culture dimension. Therefore the purpose of this paper was to investigate the effect of

* Corresponding author. ORCID ID: 0000-0003-2533-8086

(C) 2020 by the authors. Hosting by SSBFNET. Peer review under responsibility of Center for Strategic Studies in Business and Finance. https://doi.org/10.20525/ijrbs.v9i3.687 
organizational culture on strategy implementation process of Private chartered universities in Kenya. The aim of the paper was also to establish whether Clan culture has positive significant effect on strategy implementation process of Private chartered universities in Kenya. The paper highlights the statement of the problem, theoretical background, Empirical studies, methodology, hypothesis development, results and discussion, and conclusions.

The dire need of organizational culture and its effect on private institutions of higher learning and understanding of organizational culture will help university leaders to manage change more effectively and efficiently. This has hindered the ability to address the challenges that the universities face (Tierney, 2008). Some of the studies that have been done previously have observed organization culture as one of the factors affecting implementation of strategies (Fowler, 2002; Schein, 2009). These studies found that culture is one of the most important factors of success or failure with the greatest possibility to affect organizational improvement; and organizational culture carries critical forces that need to be considered in strategy implementation. Rick (2013) has further noted that when culture accepts strategy, implementation is scalable, it is sustained and repeated, and higher education institutions must monitor it to be able to understand and engage their institutions in this process. There has been an increased interest in understanding the organizational culture in Kenyan universities; but there is an evident limited literature on the knowledge of organizational culture that brings about successful strategy implementation. Theoretical studies on organizational culture and empirical studies on successful strategy implementation have mostly been carried out in developing world (Okumus, 2001, Ahmadi, et al, 2012).

Several studies in Kenya have been done on factors and challenges that are experienced on strategy implementation in higher education institutions in Kenya (Chiuri, 2015, Isaboke, 2013). Despite much research on challenges of strategy implementation, research needs to be done on the effect of organizational culture in Private chartered universities in Kenya. Past studies in higher learning institutions in American, Australian and Chinese contexts have used CVF framework to measure the university culture values that are consistent in those contexts (Lamond, 2003; Yu \&Wu, 2009). There is need to study the effect of organizational culture and the implementation of strategies in using CVF framework in the Kenyan context. Murage-Macharia and Kanyua (2016) point out that it is important to be aware of any factors that would be hinder implementation of strategy in compliance with Commission for University Education. Identification of these cultural factors need to be addressed and hence, the need to study the effect of organizational culture on strategy implementation. This study therefore investigated on the effect of organizational culture on strategy implementation process of Private chartered universities in Kenya, and to fill the above mentioned gap.

The reminder of this study is organized as follows. The next section provides a review of extant literature. The third section introduces methodology and data. Finally, conclusions and implications of the study are presented in the final section.

\section{Literature review}

\section{Theoretical background}

Contingency theories predict that good leadership is situational specific. These theories focus on forces external to the organization rather than the internal orientation of the leader. Some contingency theories examine forces that either substitute for or counteract leadership. Participants in these theories share evolving meanings, values, and beliefs that constitute the organization's culture. Leaders may influence culture, but culture cannot be 'managed' in the traditional sense of the word; but it can significantly constrain leaders (Nidiffer \& Bashaw, 2001). Several organizational theorists within higher education emphasize the importance of culture. When institutions are viewed as cultural systems, effective leaders give symbolic meaning to events which seem perplexing, senseless, or chaotic. A contingency theory that predicts the nature of appropriate or effective leadership is best understood within the context of the organization. Universities and colleges are described as various institutional types: Bureaucracy, colleguim, political system, or organized anarchy (Nidiffer \& Bashaw, 2001). This theory is important for this study because it predicts the nature of appropriate or effective leadership which is best understood within the context of the organization, and Hierarchy culture is simply identified through the domination of rule, system and procedure.

The Open Systems theory was developed by a Hungarian biologist called Ludwig Von Bertalanffy in 1928 (Olum, 2004). The foundation of systems of theory is that all the components of an organization are interrelated, and that changing one variable might affect many others, or if one subsystem fails, the whole system is put in jeopardy. In this regard, organizations are viewed as open systems, continually interacting with the environment. These parts that share feedback among each other can be looked as consisting of four aspects namely: inputs which comprise resources such as raw materials, money, technology, and people; processes, such as planning, organizing, motivating and controlling; outputs such as products and services and enhanced systems productivity. This implies that when one part of the systems is removed, the nature of the system is changed as well. Systems theory helps managers to look at the organization more broadly and recognize the interrelationships among the various parts of the organization and how they are related to each other (Olum, 2004). Universities are beneficiaries from a strong open system's approach which helps them to understand the environmental demands and the resulting adaptation in policy and the implementation of their strategies. The PESTEL tool gives factors that put pressure on the Private universities in Kenya like the political environment (Mwanje, 2016). This model would be fitting for the proposed higher education mixed economy that is shaped by the market demands and also a knowledge economy (Santiago, et al., 2008). This theory is therefore relevant for this study because it is fitting for the organizational culture and implementation of strategies in Private chartered universities. 
Human resource development (HRD) is defined as a process of developing and unleashing human potential expertise through the organization development and personnel training and development so as to improve performance. Training is the process of systematically implementing organizational change in order to get better results whereas performance entails the organization, work process and individual or group levels (Swanson \& Holton, 2009). The core beliefs of human resource development are three. First, that organizations are human-made entities that rely on human expertise establish and achieve goals. Second, that human expertise is maximized and developed through human resource development and should be done for the mutual short term and long term benefit of both the organization and the individuals involved. Third, professionals are advocates of individual or group work process and organization integrity (Ruona \& Gibson, 2004; Swanson \& Holton, 2009). Achieving successful strategy implementation in the Private chartered universities means that the university management and the employees must be trained well and own the strategy to get the expected results of the organization, in terms of achieving its goals, profitability, efficiency and effectiveness of their products and services. The HRD process and components alluded to in this research for the implementation of strategies in Private chartered universities has the potential of harmonizing, supporting and shaping the institutions of higher learning (Chiuri, 2015). Ashmos, et al. (2002) indicate that when managers, other organizational employees are involved, combined with other organizational processes in strategy implementation are involved, this can result in a variety of institution outcomes. These are the principles in the platform of the HRD theory. Therefore, universities sharpen the skills, capabilities, competencies, and also develop managers in order to relinquish their expertise and improve their delivery in implementing strategies, hence improve the performance of the organization. The HRD process and components alluded to in this research for the implementation of strategies in Private chartered universities has the potential of harmonizing, supporting and shaping the whole institution (Chiuri, 2015).

The Competing Values Framework (CVF) is one of the models that have been applied to measure a typology of organizational culture, though it is very complicated. Though there are other typology cultures, the CVF is one of the most comprehensive and extended culture typology, and it has been used in many empirical studies (Sanz-Valle, et al., 2011; Igo \& Skitmore, 2006). The model uses two dimensions to group culture into four types. Lacatus (2013) points out that this kind of approach has allowed the analysis on organizational culture to result into various models that may be identified. A series of studies (Beytekin, et al., 2010; and McNay, 1995, have built upon that and contributed to the development of a matrix of organizational cultures, that is more detailed and sophisticated, and acknowledged under Competing Values Framework. Each quadrant resulted from crossing the two basic dimensions represents a particular model of organizational culture. The quadrants of the CVF refer to hierarchy, market, clan, and adhocracy cultures, respectively (Beytekin, et al., 2010). The type of culture - clan, adhocracy, hierarchy, or market is decisive as the organizational effectiveness is more concerned than congruence and strength (Lacatus, 2013). The strength of this model is that it allows researchers to compare across organizations and generalize about culture with high sample sizes. The CVF can also be used as a conceptual model to do qualitative research and to explore the reasons and process of organizational culture change. Moreover, this is a promising research field to study the prerequisite conditions of different culture types in the CVF and the relationships between organizational culture and other variables such as organizational effectiveness, and employee satisfaction (Yu \& Wu, 2009). Further, in using the competing values framework, Smart and John (1996) concluded that some types of culture have a stronger positive relationship with traditional measures of the organizational effectiveness of colleges and universities than other culture types. But they noted that it is critically important that the culture be strong in order to achieve maximum effectiveness. This study used this framework to assess organizational culture in Private chartered universities in Kenya.

\section{Empirical studies and hypothesis development}

Various empirical studies have been conducted on organizational culture and the implementation of strategy. Some studies have consistently cited organizational culture as a key determinant of successful strategy implementation. Some researchers indicated that there is a positive link between organizational culture and performance (Fay \& Denisson, 2003; Pirayeh et al., 2011). Studies done in Iran on the relationship between organization culture and strategy implementation showed that clan and adhocracy cultures prepare amenable surroundings for their employees to receive more relevance with structural factors of strategy implementation. The reason may be because the extent of a structure tolerates deviations from mechanistic body and also present freelance in organizational behavior which is crucial in strategy implementation (Ahmadi, et al, 2012). Research findings in three government institutions of human capital managers show that existing cultures are hierarchy and clan, but the preferred culture is clan (Sensusea, et al., 2015). Organizational culture is a crucial element for organizational effectiveness and excellent employee performance. Clan and Adhocracy cultures are the most preferred cultures for the employees of the higher learning institutions' libraries in the United Arab Emirates (Chidambaranathan \& Sakthi, 2016).

Cameron and Freeman (1991) study revealed that clan cultures were the most numerous type of culture among the congruent cultures in their sample. The study showed that effectiveness of institutions is closely associated with the type of existing culture and internal congruence. The research also indicated that in a university setting, the culture that scored higher on student educational satisfaction, student personal development, faculty and administrator employment satisfaction, and organizational health was clan culture (Cameron \& Freeman, 1991). Gregory, et al., (2009) in their study found a positive relationship between clan culture and patient satisfaction in healthcare facilities. This type of culture is relevant to this study because universities need to have family-type culture that enables them to implement their strategies. The clan culture is full of common goals and shared values, an atmosphere of mutual help and collectivity, and an emphasis on employee evolvement and empowerment. This type of culture is revealed under certain 
conditions such as a stable membership and a relatively long history, thick interactions among members and absence of institutional alternatives (Yu \& Wu, 2009).

Ahmadi et. al. (2012) focused on the study on relationship between organizational culture and strategy implementation - typologies and dimensions. The findings showed that clan culture effects significantly on strategy implementation. The study concluded that there is sufficient evidence linking cultural traits and organizational effectiveness, and these findings are in line with previous studies done on the relationships between organizational culture and organization's performance indicators (Pirayeh, et al, 2011). Cameron and Freeman (1991) in their study of organizational culture in 334 institutions of higher education produced evidence for the validity of the Competing Values Framework. The sample of organizations was a representative of an entire population of colleges and universities in the United States. The study concluded that there is no organization that is characterized by one culture, but dominant cultures are clearly evident in most institutions. Institutions that had Clan-type culture (collaborative) were most effective in domains of performance relating to morale, satisfaction, internal communication, and supportiveness had attributes that were consistent with Clan values.

In Kenya, there have been several attempts to understand organization culture. Mutai (2015) did a study on organizational culture and strategy implementation at Airtel Kenya concluded that flexible cultures are easily adapted to modifications. The findings of the study showed that clan and adhocracy cultures prepare favorable environment for their employees to receive more relevance with structural factors of strategy implementation. Clan culture creates understanding between team members, but it can also cause delays in deliverables during strategy implementation when compromised. Teamwork in this culture is vital to make sure that the organization is moving in one direction and ensure that all strategies are well implemented (Mutai, 2015). Further, the study revealed that there is a high significant relation between strategic emphases in culture of an organization and its strategy implementation. Kimemia (2013) did a study on organizational culture and corruption and found that clan dimension was the most dominant culture among the selected organizations, and it had the highest mean score.

Strategy implementation is challenged by global competition; U.S.A. companies, both in the service and manufacturing sector are embracing and implementing TQM. But higher education institutions, that is, universities and colleges have been slow in adopting this approach (Soni, et al., 2000). In Czech Republic, there is a focus on a more strategic use of e-Learning and this has become important as the environment in which higher education institutions operate changes. Over the last decades higher education institutions have experienced profound changes in their external environment affecting both their primary and secondary processes of education, research and organization (Boezerooij, 2006).

Studies in Africa, especially in the University of Ghana on strategic planning in public universities found that regarding the effect of culture on strategy implementation, the values that existed in the universities do not effectively inform the behaviors of the members of these institutions (Ofori \& Atiogbe, 2012). In Botswana, there were strong observations that the University of Botswana needed to improve the implementation process through improved delivery of projects, better monitoring and evaluation and enhanced strategic alignment of its functions, particularly planning, resource allocation and quality. For effective implementation of strategies, the University will require to have good governance, significant change management, leadership and organizational development (Council, 2008). This should be backed up by a stronger and deepening level of institutional planning and research, an approach to quality that can deliver excellence and improved processes to deliver excellent levels of service (Council, 2008). In Tanzania, the Ministry of Higher Education, Science and Technology through Parliament in 2005 passed a new Act for the universities which allows more autonomy and implementation of their strategies. In addition, the Ministry of Lands and Human Settlements has been instrumental in getting the university in Tanzania to implement its land policy (Luhanga, 2006). In Kenya, studies show that there are challenges of strategy implementation and that institutional culture plays an important role in determining the success of strategic planning and implementation in any organization. The compatibility of the organization's culture to new strategic changes is an important measure in strategy implementation and mitigation of any challenges that may arise during implementation. Lack of synergy between strategy and culture may obstruct the smooth implementation of strategy by creating resistance to change. It is important that the culture of an organization be well-suited with the strategy being implemented because where there is incompatibility between strategy and culture, it can lead to a high organizational resistance to change and lack of motivation, which can frustrate the effort to strategy implementation (Musyoka, 2011).

\section{Methodology}

The study employed descriptive design of cross-sectional nature. Cross-sectional survey design collect data at one specific point in time and it is used to determine the current beliefs, values, behaviors, attitudes or characteristics of a given population (Cottrell \& Mckenzie, 2005). Jones (2015) has observed that cross-sectional survey designs are perhaps the most commonly used designs in the social sciences. This study adopted cross-sectional survey research design to sample the population of a cross-section of Private chartered universities in Kenya. The accessible population was middle level management, academic staff and students' leaders. Middle level management includes the academic registrars, deans of schools, chairmen/heads of departments, and program directors. Academic staff included the professors, associate professors, senior lecturers, lecturers, and assistant lecturers. The selection criteria for participants included experience, position, and seniority and the participants with senior experience in the study were appropriate to answer the research questions and to represent the population. A sample size of 10 institutions has been determined. These universities that have been selected are Religious-affiliated, particularly protestant and catholic. These universities that were 
established by churches, missionaries, and religious people have some similarities, and data is easy to be comparable. The formula that was used is given by Mugenda and Mugenda (2012). This study used stratified sampling, simple random sampling, and multistage sampling. The target sample size was 198 participants.

Kothari (2004) confirms that questionnaires are cheaper, free from bias, and participants have time to answer the questions, and hence findings becomes more dependable and reliable. A likert scale was employed to measure the ratings of items by participants in relation to various variables under investigation. Likert scales are preferred because they are easy to complete and in conducting analyses on the data (Golembiewski, 2005). The interview guide was used to clarify information from the questionnaire. The researcher interviewed participants from the middle level management. The study used self administered questionnaires to be able to obtain quantitative data for analysis to either refute or support the hypotheses. In development of the survey questionnaire, the variables for which information was collected was identified and followed by their operational definition. Self introduction was the procedure for issuing the questionnaires to the participants. Primary data was collected through the administration of questionnaires to middle level management, academic staff, and students' leaders of Private chartered universities. Research assistants were trained and engaged to administer and follow up on the questionnaires. The specific objectives of the study were the key areas of investigation. Interviews were done to the Dean of Students, Finance Officers, Public Relations Officers, and Human Resource Managers.

In this study normality tests were done using Kolmogorov-Smirnov Shapiro-Wilk normality tests. These procedures test the same null hypothesis and the data is sampled from a normal distribution (Athanasiou, Debas \& Darzi, 2010). Breusch-Pagan was used to test the null hypothesis that the error variances are all equal versus the alternative that the error variances are a multiplicative function of one or more variables. There were two versions of Breusch-Pagan tests which were conducted, that is, Breusch-Pagan tests and Breusch-Pagan tests with robust variant. Breusch-Pagan tests the null hypothesis that heteroscedasticity is not present which imply that Homoscedasticity is present. If P-value is less than 0.05 , reject the null hypothesis. ANOVA in its simplest form provides a statistical test of whether the means of several groups are equal or not and therefore generalizes the t-test to more than two groups (Chiuri, 2015). This study used analysis of variance (ANOVA), correlation as well as regression techniques to test the study hypotheses.

\section{Results and discussion}

To know the level to which the institution encourages teamwork which facilitates successful strategy implementation (Clan culture 1), on scale of 1-5, average score of 3.75 was realized with standard deviation of 1.06 . This indicated that majority of the respondents were in agreement that the institutions normally encourage teamwork which facilitates successful strategy implementation. To establish the level to which commitment of employees has enabled effective strategy implementation (Clan culture 2). But lack of employee commitment lead to derailed implementation of some strategies (Mwanthi, 2017). The results established that an average score of 3.94 was recorded with standard deviation of 1.26 on a scale of 1-5. The finding further suggest that majority of the respondents were in agreement that commitment of employees has enabled effective strategy implementation within private chartered universities in Kenya.

To investigate the level to which respondents agree or disagree that communication by the management has caused the strategies to be implemented effectively within private chartered universities in Kenya (Clan culture 3) the findings were clear with majority of the respondents strongly agreeing that communication by the management had caused the strategies to be implemented effectively. This was confirmed with the fact that average score was 4.11 with standard deviation of 1.13 . To measure the level to which respondents approves or disapproves the fact that the institution emphasizes human resource training (Clan culture 4), the findings suggest that majority of the respondent strongly approve or agree that the institutions emphasizes human resource training in private chartered universities in Kenya because average score of 4.20 and standard deviation of 1.37 were recorded.

To show that there is more training of employees in the institution which is good for successfully implementing strategies within private charted universities in Kenya (Clan culture 5), the result was not disappointing since the respondents were in agreement that there was more training of employees in the institutions which is good for implementation of strategies. This was confirmed by the fact that the mean score was 3.77 which was recorded within arrange of 1-5 and standard deviation of 1.07. Concerning whether the institution invests in improving people skills which are essential in ensuring success in strategy implementation (Clan culture 6), the finding suggest that the respondents disagreed that the institution invests in improving people skills which are essential in ensuring success in strategy implementation because mean score of 2.56 and standard deviation of 1.00 was obtained. To ascertain whether the institution awards incentives to employees who perform well (Clan culture 7), the respondents again disagreed that the institution awards incentives to employees who perform well in private charted universities in Kenya and this was confirmed with mean score of 4.12 and standard deviation of 1.04 . 
Table 1: Clan culture descriptive analysis

\begin{tabular}{llll}
\hline Clan culture & Mean & Std. Deviation & Analysis N \\
\hline Clan culture 1 & 3.75 & 1.06 & 198.00 \\
\hline Clan culture 2 & 3.94 & 1.26 & 198.00 \\
\hline Clan culture 3 & 4.11 & 1.13 & 198.00 \\
\hline Clan culture 4 & 4.20 & 1.37 & 198.00 \\
\hline Clan culture 5 & 3.77 & 1.07 & 198.00 \\
\hline Clan culture 6 & 3.56 & 1.00 & 198.00 \\
\hline Clan culture 7 & 4.12 & 1.04 & 198.00 \\
\hline
\end{tabular}

In qualitative analysis, results showed that benchmarking is one of the techniques and culture that is a continuous systematic measurement and comparisons aimed at seeking fresh approaches, implementing improvements and reviewing the benefits in higher education (Magutu, et al., 2011). To rate the institution's benchmark best practices before they adopt new ways of working, $35 \%$ respondents indicated that their institutions benchmark with other institutions before they adopt new ways of working. The responses were under $50 \%$ but the second highest was $29.1 \%$ responses who rated their universities $75 \%$ as using benchmark best practices. But $100 \%$ response had $6.9 \%$ respondents who indicated that their institutions had the best practices of benchmark. The findings indicate that majority of Private chartered universities in Kenya have a culture of using the benchmark best practices before they adopt new ways of working. Results in Table 2 show the summary of the findings.

Table 2: Institution benchmark best practices

\begin{tabular}{lcc}
\hline Response & Frequency & Percent \\
\hline $0 \%$ & 2 & 2.35 \\
\hline $25 \%$ & 23 & 26.74 \\
\hline $50 \%$ & 30 & 34.88 \\
\hline $75 \%$ & 25 & 29.06 \\
\hline $100 \%$ & 6 & 6.97 \\
\hline Total & $\mathbf{8 6}$ & $\mathbf{1 0 0 . 0 0}$ \\
\hline
\end{tabular}

\section{Normality test}

Skewness and kurtosis values were imputed on the basis of moments. The values of Skewness and Kurtosis should be zero if the data is normally distributed otherwise the data is said to be skewed or highly peaked but the acceptable range of values is -2 and +2 (Field, 2009). In this study skewness and kurtosis values were summarized as follows and from the finding, it was clear that all the variables were within acceptable range of skewness. Table 3 shows the results. In this case values between -2 and +2 are considered normal. In addition, Kolmogorov-Smirnov and Shapiro-Wilk tests can be conducted to test whether the data set is normally distributed (Sarstedt \& Mooi, 2014).

Table 3: Skewness and kurtosis

\begin{tabular}{lllllllll}
\hline Variables & $\mathbf{N}$ & Mean & Std. Dev & Skewness & Kurtosis & Conclusion \\
\cline { 2 - 7 } & & Statistic & Statistic & Statistic & $\begin{array}{l}\text { Std. } \\
\text { Error }\end{array}$ & Statistic & $\begin{array}{l}\text { Std. } \\
\text { Error }\end{array}$ \\
\hline Clan culture & 198 & 3.6629 & .65345 & .147 & .173 & .110 & .344 & $\begin{array}{l}\text { Normally } \\
\text { Distributed }\end{array}$ \\
\hline
\end{tabular}

\section{Kolmogorov- Smirnov and Shapiro Wilk test for normality}

Normality of a data set was tested using Kolmogorov-Smirnov and Shapiro Wilk for all the variables which were under consideration. Kolmogorov-Smirnov and Shapiro Wilk compare the scores in the samples and check whether they have the same mean or standard deviation (Sarstedt \& Mooi, 2014). The findings for Kolmogorov-Smirnov showed that, the p- values were greater than 0.05 for the variables (clan culture and strategy implementation) indicating that the distributions were normally distributed. Shapiro-Wilk test results also showed that two variables were normally distributed. The details of the findings are shown in Table 4 .

Table 4: Kolmogorov-Smirnov and Shapiro-Wilk

\begin{tabular}{lllllllll}
\hline Variables & \multicolumn{2}{l}{ Kolmogorov-Smirnova } & \multicolumn{4}{c}{ Shapiro-Wilk } \\
\cline { 2 - 8 } & Statistic & $\begin{array}{l}\text { Degree } \\
\text { freedom }\end{array}$ & of & P-value & Statistic & $\begin{array}{l}\text { Degree } \\
\text { freedom }\end{array}$ & $\begin{array}{l}\text { of } \\
\text { value }\end{array}$ \\
\hline Clan culture & .061 & 198 & .070 & .989 & 198 & .155 \\
\hline
\end{tabular}




\section{Normality using $Q-Q$ plot}

In addition to the above mentioned test, normality of the data was also tested using quantile- quantile plot also known as Q-Q plot for the dependent variable (Corporate strategy implementation) based on the finding as shown in Figure 1, it was clear that the majority of the observed values were falling along a straight line. This therefore means the variable (Corporate strategy implementation) was normally distributed. An extension of Q-Q plot was also done on the independent variable; clan culture indicated on figure 1. These results were consistent with the earlier findings based on skewness and Kurtosis test, Kolmogorov- Smirnov and Shapiro Wilk test.

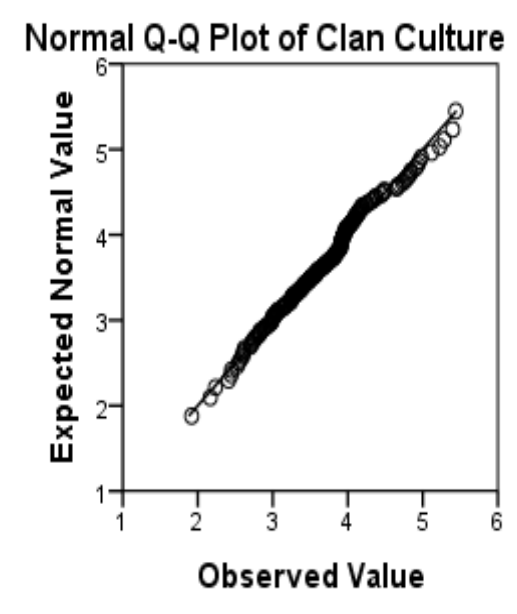

Fig.1: Normal Q-Q plot of Clan culture

\section{Correlation analysis}

Correlation analysis clearly shows the strength of the relationship between variables. In this study, Pearson product moment correlation coefficient was employed to establish the relationship between the predictor/explanatory variable. In this study, the correlation analysis was conducted, and the findings are summarized in Table 4.5. The findings also suggest that there was no significant relationship between the independent variables since all the p-values were more than 0.05 . Since the p-values were higher, there was no problem of multi-collinearity among the explanatory variables. The findings were also supported with $\mathrm{R}$ values which majority, were less than 0.4 .

Table 5: Correlation analysis of independent variable

\section{Clan culture}

\begin{tabular}{lll}
\hline Clan culture & Pearson Correlation & 1 \\
\cline { 2 - 2 } & P-value (2-tailed) & 198 \\
\cline { 2 - 2 } & $\mathrm{N}$ & 198 \\
\hline
\end{tabular}

Besides product moment correlation coefficient, scatter plot between Strategy implementation and the independent variable (Clan culture) was performed to test linearity between independent variables and dependent variable and the result in figure 2 clearly suggest that there was some linear relationship between Clan culture with strategy implementation, that is, an improvement in Clan culture will lead to increase in Strategy implementation. 


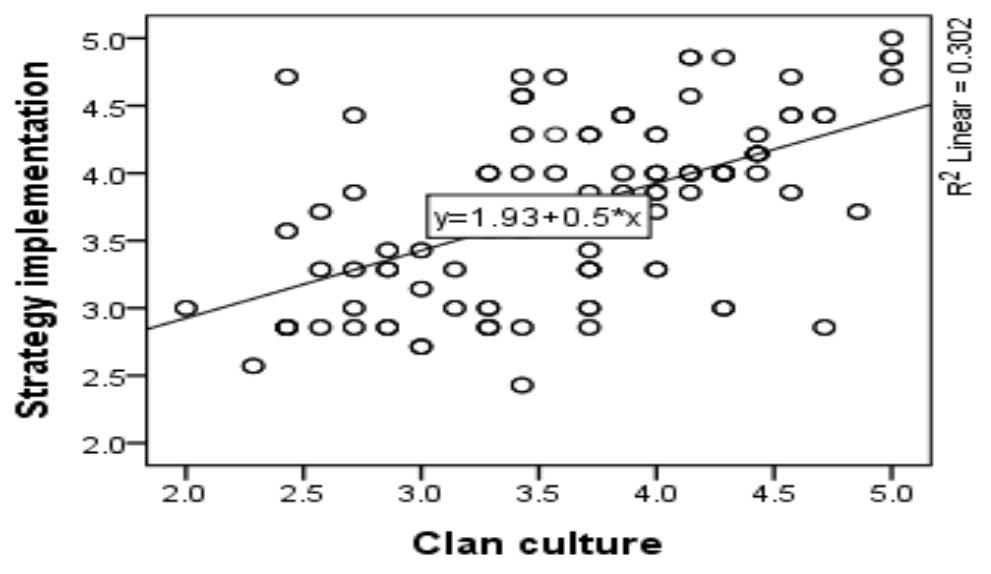

Fig. 2: Scatter plot between strategy implementation and Clan culture

\section{Tests for regression model assumptions}

Multicollinearity was tested using Variance Inflation Factor (VIF) which is a reciprocal of tolerance. Some scholars suggest that a VIF value more than 10 (VIF $\geq 10$ ) indicate that there is a problem of multicollinearity. According to Montgomery (2001) the threshold value for existence of multicollinearity is 10 and above with corresponding tolerance statistic values below 0.1 indicating a serious problem while those below 0.2 indicating a potential problem. The results in Table 6 indicate that the Variance Inflation Factor (VIF) value for Clan culture was established to be 1.986 while tolerance statistic value reported as 0.503 .

Table 6: Multicollinearity

\begin{tabular}{lllll}
\hline Variables & $\begin{array}{l}\text { Collinearity } \\
\text { (model 1) }\end{array}$ & Statistics & without moderator & \multicolumn{2}{l}{$\begin{array}{l}\text { Collinearity Statistics with moderator } \\
\text { (model 2) }\end{array}$} \\
\hline (Constant) & Tolerance & VIF & Tolerance & VIF \\
\hline Clan culture & .503 & 1.986 & .188 & 5.315 \\
\hline
\end{tabular}

Test for heteroscedasticity and homoscedasticity

Heteroscedasticity in a study normally occurs when the variance of the errors varies across observation (Long \& Ervin, 2000). Breusch-Pagan was used to test the null hypothesis that the error variances are all equal versus the alternative that the error variances are a multiplicative function of one or more variables. There were two versions of Breusch-Pagan tests which were conducted, that is, Breusch-Pagan tests and Breusch-Pagan tests with robust variant. Breusch-Pagan tests the null hypothesis that heteroscedasticity is not present which imply that Homoscedasticity is present. If P-value is less than 0.05 , reject the null hypothesis. A large chi-square value greater than 9.22 would indicate the presence of heteroscedasticity (Sazali, et al., 2010). In this study, the chi-square, a value resulting from each regression model where the independent variable was considered individually as model indicated that heteroscedasticity was not a problem for the entire models. The null hypothesis tested was that variance is Constant versus the alternative that variation was not constant.

Table 7: Breusch-Pagan and white test for Heteroscedasticity

\begin{tabular}{|c|c|c|c|c|}
\hline Test & & Breusch-Pagan test & White's test & $\begin{array}{l}\text { Breusch-Pagan } \\
\text { (Robust variant) }\end{array}$ \\
\hline & Hypothesis & $\begin{array}{l}\text { Ho:Heteroskedasticity not } \\
\text { present }\end{array}$ & $\begin{array}{l}\text { Ho:Heteroskedasticity not } \\
\text { present }\end{array}$ & $\begin{array}{l}\text { Ho:Heteroskedasticity not } \\
\text { present }\end{array}$ \\
\hline \multirow[t]{2}{*}{$\begin{array}{l}\text { Regression for } \\
\text { Clan culture }\end{array}$} & Model 1 & $\begin{array}{l}\text { Test statistic: LM = } \\
0.000109095\end{array}$ & Test statistic: $\mathrm{LM}=0.118$ & $\begin{array}{l}\text { Test statistic: } \mathrm{LM}= \\
0.000160671\end{array}$ \\
\hline & & $\begin{array}{l}\text { with p-value }=\mathrm{P}(\text { Chi- } \\
\text { square(1) }>0.00011)= \\
0.991666\end{array}$ & $\begin{array}{l}\text { with p-value }=P(\text { Chi- } \\
\text { square }(2)>0.118002)= \\
0.942706\end{array}$ & $\begin{array}{l}\text { with p-value }=\mathrm{P}(\text { Chi- } \\
\text { square }(5)>6.97974)= \\
0.222151\end{array}$ \\
\hline
\end{tabular}

\section{Test for linearity - Clan culture}

To establish out whether there was linear relationship between Clan culture and Strategy implementation, Pearson moment's correlation coefficients was employed as suggested by Cohen, West and Aiken, (2003). The result is presented on table 4.8. The findings indicate that the variables Strategy implementation and Clan culture had a positive relationship indicated by a correlation coefficient value of $0.549^{* *}$. This suggests that there was a linear positive relationship between Clan culture and Strategy 
implementation which implies that an increase in Clan culture would lead to a linear increase in strategy implementation process of the Private chartered universities in Kenya.

Table 8: Clan culture Correlations Coefficients

\begin{tabular}{llll}
\hline Variable & & Strategy implementation & Clan culture \\
\hline Strategy implementation & Pearson Correlation & 1 & $.5499^{* *}$ \\
\cline { 2 - 3 } & P-value (2-tailed) & .000 \\
\cline { 2 - 3 } & $\mathrm{N}$ & 198 & 198 \\
\hline Clan culture & Pearson Correlation & $.549^{* *}$ & 1 \\
\cline { 2 - 3 } & $\mathrm{P}$-value (2-tailed) & .000 & 198 \\
\cline { 2 - 3 } & $\mathrm{N}$ & 198 & \\
\hline$* *$ Correlation is significant at the 0.01 level (2-tailed). & & \\
\hline
\end{tabular}

\section{Hypothesis testing}

The first objective was to examine the effect of Clan culture on strategy implementation process of Private chartered universities in Kenya. The null hypothesis which stated that: There was no positive significant relationship between Clan culture and strategy implementation process of Private chartered universities in Kenya, against the alternative that there was a positive significant relationship between Clan culture and strategy implementation process of Private chartered universities in Kenya was tested. By conducting simple linear regression, preliminary findings reveal that there was some positive effect of clan culture on implementation of corporate strategy in Private chartered universities in Kenya this was indicated on model summary table where the strength of the relationship between predictor variable and the response variable is shown using correlation $(\mathrm{R})$ or coefficient of determination $\mathrm{R}$ square. The R-square is a value which how well the model fits the data. An R-square value which is nearer to 1.0 suggests that the dependent variable entirely depends on the independent variables while a value nearer to 0 indicates no relationship at all between the explanatory variables and the dependent variable (Ming'ala, 2002). Table 9 shows the regression analysis findings between Strategy implementation and Clan culture. From the Table 9, the value of R-square value was 0.190 implying that $19.0 \%$ of Strategy implementation was explained by Clan culture. The Analysis of Variance Table 10 was further used to illustrate the findings. In the ANOVA table, the p-value was 0.000 which was less than 0.05 . This therefore, implied that there was a significant relationship between Clan culture and implementation of corporate strategy in Private chartered universities in Kenya. This means that Clan culture affects strategy implementation process of Private chartered universities in Kenya.

From the coefficient Table 11, t-test was also used to test the relationship between the predictor variable Clan culture and Strategy implementation and there was significance relationship between the two variables with $\mathrm{p}$-value $=0.000<0.05$ for the model. The regression equations between Strategy implementation and Clan culture for the model can be expressed as; $\mathrm{Y}=1.748+0.544 \mathrm{X}_{1}$. The model indicated that for every unit of Clan culture the value of strategy implementation process of Private chartered universities in Kenya changes by 0.485 . Based on the regression analysis, these results were valid and with this preliminary finding, it was clear that the null hypothesis was to be rejected and the alternative hypothesis accepted. For this reason, the fundamental and conclusion was that Clan culture had significant influence on implementation of corporate strategy in Private chartered universities in Kenya.

Table 9: Model summary for regression Analysis for Clan culture and Strategy implementation

\begin{tabular}{|c|c|c|c|c|c|c|}
\hline Model & $\mathbf{R}$ & R Square & $\begin{array}{l}\text { Adjusted } \\
\text { Square }\end{array}$ & $\mathbf{R}$ & $\begin{array}{l}\text { Std. Error of the } \\
\text { Estimate }\end{array}$ & $\begin{array}{l}\text { Durbin- } \\
\text { Watson }\end{array}$ \\
\hline 1 & $.569 \mathrm{a}$ & .324 & .321 & & .55117 & 1.758 \\
\hline $\begin{array}{ll}\text { a. } & \mathrm{P}_{1} \\
\text { b. } & \mathrm{D} \\
\end{array}$ & $\begin{array}{l}\text { onstant) } \\
\text { iable: } S\end{array}$ & $\begin{array}{l}\text { model } 1 \\
\text { mentation }\end{array}$ & & & & \\
\hline
\end{tabular}

Table 10: ANOVA for Clan culture (X1)

\begin{tabular}{lllllll}
\hline Model & & Sum of Squares & $\begin{array}{l}\text { Degree } \\
\text { freedom }\end{array}$ & Mean Square & F & P-value \\
\hline $\mathbf{1}$ & Regression & 28.550 & 1 & 28.550 & 93.979 & $.000 \mathrm{~b}$ \\
& & & & & \\
\cline { 2 - 6 } & Residual & 59.544 & 196 & .304 & & $.000 \mathrm{~b}$ \\
\cline { 2 - 6 }
\end{tabular}

a. Response Variable: Strategy implementation

b. Predictor: (Constant), Clan culture 
Table 11: Coefficients for Clan culture $\left(\mathrm{X}_{1}\right)$

\begin{tabular}{|c|c|c|c|c|c|c|}
\hline \multirow{2}{*}{\multicolumn{2}{|c|}{ Model }} & \multicolumn{2}{|c|}{$\begin{array}{l}\text { Unstandardized } \\
\text { Coefficients }\end{array}$} & \multirow{2}{*}{$\begin{array}{l}\text { Standardized } \\
\text { Coefficients } \\
\text { Beta }\end{array}$} & \multirow[t]{2}{*}{$\mathbf{t}$} & \multirow[t]{2}{*}{ P-value } \\
\hline & & B & Std. Error & & & \\
\hline \multirow[t]{2}{*}{1} & (Constant) & 1.748 & .207 & & 8.434 & .000 \\
\hline & Clan culture & .544 & .056 & .569 & 9.694 & .000 \\
\hline
\end{tabular}

Multivariate regression analysis was employed to investigate the overall effects of independent variable on the dependent variable. For this reason, after performing multiple linear regression, the section attempts to lay bare the results of the overall effects of the explanatory/predictor variable which mainly consist of Clan culture on the dependent variable which was strategy implementation process of Private chartered universities in Kenya taking note that the overall model for the study was; $\mathrm{Y}=\beta_{0}+\beta_{1} \mathrm{X}_{1}+e$

where:

$\mathrm{Y}=$ Strategy implementation

$\mathrm{X}_{1}=$ Clan culture

The overall fitness of the model was determined using coefficient of determination also known as R-square which can also be extended to R-square adjusted. In this study, summary of the results were presented in Table 12 and the findings clearly shows that the model used in the study was satisfactory as it was supported by coefficient of determination R-square of 0.545 in the absence of moderator and R-square value of 0.660 in the presence of moderator. Coefficient of determination value obtained above implies that the explanatory/independent variable contributes $54.5 \%$ and $66.0 \%$ in the absence of moderator and the variations in the response variable (strategy implementation process of Private chartered universities in Kenya).

To confirm the fitness of the overall model of the study, analysis of the variance (ANOVA) was employed. In this case the main interest was to establish the fitness of one model. Table 12 shows that the overall model was fit enough with F statistic of 80.991 and the reported p-value of 0.000 which was far much less than the conventional probability of 0.05 significance level which was chosen arbitrarily as the risk incurred in committing type I error (rejecting the null hypothesis while it is correct). The results showed that the independent variable was good predictor of strategy implementation process of Private chartered universities in Kenya. The overall Regression Coefficients results in Table 13 clearly gives an illustration on how positive and significant relationship between Strategy implementation (dependent variable) and Clan culture (predictor variable). From the finding, the overall model obtained was expressed as: $\mathrm{Y}=0.221+0.109 \mathrm{X}_{1}$ in the absence of moderator. The findings were evidence that for every unit change in the variable, the response variable will definitely lead to increase or decrease in the value of strategy implementation process of Private chartered universities in Kenya.

Table 12: Overall model summary for regression analysis for the variable

\begin{tabular}{|c|c|c|c|c|c|c|}
\hline Model & $\mathbf{R}$ & R Square & $\begin{array}{l}\text { Adjusted } \\
\text { Square }\end{array}$ & $\mathbf{R}$ & $\begin{array}{l}\text { Std. Error of the } \\
\text { Estimate }\end{array}$ & $\begin{array}{l}\text { Durbin- } \\
\text { Watson }\end{array}$ \\
\hline 1 & $.738 a$ & .545 & .536 & & .45566 & 1.822 \\
\hline \multicolumn{7}{|c|}{ a. Predictors: (Constant), Clan culture } \\
\hline b. Depe & ble: Str & itation & & & & \\
\hline
\end{tabular}

\section{Optimal Model}

The key finding based on the tests conducted in the study was obvious that the explanatory variable: Clan culture, had effect on the response variable (Implementation of corporate strategy in Private chartered universities in Kenya) as shown in Table 4.13.

Table 13: Overall Regression Coefficients

\begin{tabular}{lllll}
\hline No & Hypothesis & t- value & P- value & Decision \\
\hline 1.Ho & $\begin{array}{l}\text { Clan culture has no effect on implementation of strategy in } \\
\text { Private chartered universities in Kenya. }\end{array}$ & 3.114 & .001 & Reject Ho \\
\hline
\end{tabular}

\section{Conclusions}

Based on findings of the study, it was concluded that organizational culture influences the implementation of corporate strategy in Private chartered universities in Kenya. Private Chartered universities are therefore expected to embrace this culture because it leads to successful implementation of strategies in these universities. The results established that institutions that encouraged teamwork facilitated successful strategy implementation because teamwork affected the performance of the organization to a very great extent. 
Commitment of employees enables effective strategy implementation within private chartered universities in Kenya. Communication by the management also causes the strategies to be implemented effectively. Results showed that some Private universities never communicated strategies with their employees which made it difficult to implement strategies that they were not aware of. The findings revealed that the institutions did not award incentives to employees who performed well in Private charted universities in Kenya. These universities do not also invest in improving people skills which are essential in ensuring success in strategy implementation process. Motivational incentives work as a tool for achieving the targeted strategic goals, and as a result the employees are committed to strategy implementation. In qualitative analysis, the results established that majority of Private chartered universities in Kenya have a culture of using the benchmark best practices before they adopt new ways of working. Leadership in these institutions that exemplified innovation helped strategy implementation. Additional resources in the institution enhance strategy implementation.

The results in the regression analysis were clear that the null hypothesis was to be rejected and the alternative hypothesis accepted. For this reason, the fundamental and conclusion was that Clan culture had significant influence on implementation of corporate strategy in Private chartered universities in Kenya. The results established that there was a linear positive relationship between Clan culture and Strategy implementation which implies that an increase in Clan culture would lead to a linear increase in Strategy implementation in Private chartered universities in Kenya. The linear relationship between Clan culture and Strategy implementation using Pearson moment's correlation coefficients was employed and the results established that the variables Strategy implementation and Clan culture had a positive relationship. This suggested that there was a linear positive relationship between Clan culture and Strategy implementation which implied that an increase in Clan culture would lead to a linear increase in Strategy implementation in the Private chartered universities in Kenya.

The University Management needs to make sure that there is level of commitment of university staff to organizational values. There should be involvement or participation and consultation of different stakeholders as directed by the Management. The first implication of the study was that university leaders need to have proper, consistent and effective communication especially with regard to new policies and changes or the culture of communication and work ethic of the leadership. The study showed that poor communication with key stakeholders means that some are always lagging behind generating unnecessary conflicts and disagreements instead of implementing their strategies. The study therefore recommends that university leadership and other stakeholders should communicate effectively the formulated strategies to enable their staff to implement these strategies.

This study concentrated on effect of organizational culture on strategy implementation process of Private chartered universities in Kenya. However, there are other cultural factors that have been characterized as important elements that enable successful process of implementation of strategies. This study has few suggestions for feasible areas that could be considered for further research:

1. Further research could be done using different theories and models on both organizational culture and implementation of strategies, in order to gain a better understanding of the relevant relationship between organizational culture and strategy implementation.

2. Though the current study demonstrated the significance of organizational culture and effective strategy implementation, further studies need to be done on other organizational typologies that enable implementation of strategies in Private chartered universities in Kenya.

\section{References}

Ahmadi, S. A. A., Salamzadeh, Y., Daraei, M. \& Akbari, J. (2012). Relationship between organizational culture and strategy implementation: Typologies and dimensions. Global Business and Management Research: An International Journal, 4(3) \& 4, 286-299.

Ashmos, D. P., Duchon, D., McDaniel, R. R. Jr. \& Huonker, J. W. (2002). What a mess! Participation as a simple managerial rule to “complexity” organizations. Journal of Management Studies, 39 (2), 189-206.

Athanasiou, T., Debas, H. \& Darzi, A. (2010). Key topics in surgical research and methodology. Berlin, Heidelberg: SpringerVerlag.

Beytekin, O. F., Yalçınkaya, M., Doğan, M. \& Karakoç, N. (2010).The organizational culture at the university. The International Journal of Educational Researchers, 2010, 2(1):1-13.

Boezerooij, P. (2006). E-learning strategies of higher education institutions: An exploratory study into the influence of environmental contingencies on strategic choices of higher education delivery and support processes. Czech Republic: CHEPS/UT.

Cameron, K. S. \& Freeman, S. L. (1991). Cultural congruence, strength and type: Relationships to effectiveness. Research in Organizational Change and Development, 5, 23-58, 1991.

Chidambaranathan, K. \& Sakthi, R. V. (2016). Diagnosing the organizational culture of Higher Education Libraries in the United Arab Emirates using the Competing Values Framework. Libres, 26(2), 99-112.

Chiuri, B. W. (2015). Challenges of strategy implementation in higher education institutions in Kenya (PhD Thesis). Jomo Kenyatta University of Agriculture and Technology, Juja, Kenya.

Cohen, J, Cohen, P., West, S. G. \& Aiken, L. S. (2003). Applied multiple regression/correlation analysis for the behavioral sciences (3rd ed.). Mahwah, New Jersey: Lawrence Erlbaum Associates Publishers. 
Cottrell, R. R. \& Mckenzie, J. F. (2005). Health promotion and education research methods: Using the five-chapter thesis/dissertation model. Sudbury, MA: Jones and Bartlett Publishers.

Council (June 2008). Final draft consultative document: A strategy for excellence. The University of Botswana Strategic Plan to 2016 and beyond. University of Botswana, Botswana.

Eugene, M. \& Lynn, C. E. (2017). Research methods in the Social Sciences. Lynn University Library. Retrieved from http://lynnlibrary.libguides.com/c.php?g=549455\&p=3771803

Fay, C. F. \& Denison, D. R. (2003). Organizational culture and effectiveness: Can American theory be applied in Russia? Organizational Science, 14(6), 686-706.

Field, A. (2009). Discovering statistics using SPSS: Introducing statistical method (3rd ed.). Thousand Oaks, CA: Sage Publications Fowler, F. J. (2002). Survey Research Methods (3rd ed.). NY: Sage Publication.

Golembiewski, R. (2005). Handbook of organizational consultation (2nd ed.). New York, NY: Routledge.

Gregory, B., Harris, S., Armenakis, A. \& Shook, C. (2009). Organizational culture and effectiveness: A study of values, attitudes, and organizational outcomes. Journal of Business Research, 62(7), 673-679.

Igo, T. \& Skitmore, M. (2006). Diagnosing the organizational culture of an Austrian engineering consultancy using the competing values framework. Construction Innovation, 121-139.

Isaboke, C. M. (2015). Influence of organization culture on strategy implementation in selected universities in Kenya. International Journal of Economics, Commerce and Management, 3(9), 2015.

Johnson, G., Scholes, K., \& Whittington, R. (2003). Exploring corporate strategy: Text and Cases. New York: Pearson Education.

Jones, I. (2015). Research methods for sports studies (3rd ed.). London: Rutledge, Taylor \& Francis Group.

Kelly, M. (2010). The role of theory in qualitative health research. Family Practice, 27 (3): 285-290. Retrieved fromhttp://fampra.oxfordjournals.org/content/27/3/285.full

Kimemia, D. (2013). Organizational culture and corruption: A multiple case study of Non-governmental Organizations in Kenya. VCU Scholars Compass. Virginia Commonwealth University.

Kothari, C. R. (2004). Research methodology: Methods and techniques (2nd ed.). New Delhi: New Age International (P) Limited.

Kumar, S. (2015). Structure equation modeling basic assumptions and concepts: A novices guide. Asian Journal of Management Sciences, 03 (07), 25-28.

Lacatus, M. L. (2013). Organizational culture in contemporary university: Education facing contemporary world issues. 5thInternational Conference EDU-WORLD 2012, Bucharest University of Economic Studies. Romania: Elsevier Ltd.

Lamond, D. (2003). The value of Quinn's Competing Values Model in an Australian Context. Journal of Managerial Psychology, 18(1/2), 46-59.

Luhanga, M. (2006). Strategic planning of higher education institutions in Africa: A case study of the University of Dar-es-Salaam. Selected Papers of Beijing Forum, 2006.Procedia, Social and Behavioral Sciences.

Lund, D.B. (2003). Organizational culture and job satisfaction. Journal of Business \& Industrial Marketing, 18(3), 219-236.

Magutu, P. O., Mbeche, I. M., Nyamwange, S. O. \& Nyaoga, R. B. (2011). A Survey of Benchmarking Practices in Higher Education in Kenya: The case of public universities. IBIMA Business Review Vol. 2011 (2011), BIMA Publishing. Article ID 357694, 20 pages, DOI: 10.5171/2011.357694

McNay, Ian (1995). Universities going international: choices, cautions and conditions, in P. Blok (ed.), Policy and Policy Implementation in Internationalisation of Higher Education, Amsterdam: EAIE.

McNabb, D. E. (2002). Research Methods in Public Administration and Nonprofit Management. Armonk, NY: M. E. Sharpe.

Mingala, J. (2002). Handbook on Data Analysis Using SPSS. Nairobi. M \& O Data Experts Training and Consultant.

Montgomery, D. C., Peck, E. A. \& Vining, G. G. (2001). Introduction to linear regression analysis (Third edition). John Wiley \& Sons, Inc.

Mugenda, A. G., \& Mugenda, O. M. (2012). Research Methods Dictionary. Nairobi: Applied Research and Training services publication.

Murage-Macharia, C. N. \& Kanyua, E. (2016). Factors influencing employee turnover in private chartered Christian universities in Nairobi City County. International Journal of Innovative Development \& Policy Studies 4(3). 15-32

Musyoka, L. W. (2011). Challenges of strategy implementation in Jomo Kenyatta Foundation. International Journal of Current Research, 3(11), 301-308.

Mutai, P. K. (2015). Organizational culture and strategy implementation at Airtel Kenya (MBA Thesis), School of Business, University of Nairobi, Nairobi, Kenya.

Mwanje, M. O. (2016). Challenges of strategy implementation in selected Sugar Companies in Kenya (PhD Thesis). Jomo Kenyatta University of Agriculture and Technology, Juja, Kenya.

Mwanthi, T. N. (2017). Determinants of successful strategy implementation in universities in Kenya (PhD Thesis). Kabarak University, Nakuru, Kenya.

Nawasar, K. Shahmehr, F. S., Kamel, A. \& Vesal, S. M. (2014). Assessing the relationship between Strategy and organizational culture in an Iranian Manufacturing Industry. Asian Social Science, 10(2) DOI: 10.5539/ass.v10n21p175

Nidiffer, J. \& Bashaw, C. T. (eds.) (2001). Women administrators in higher education: Historical and contemporary perspectives. New York, NY: State University of New York. 
Ofori, D. \& Atiogbe, E. (2012). Strategic planning in public universities: A developing country perspective. Journal of Management and Strategy, Vol. 3, No. 1, February 2012. doi:10.5430/jms.v3n1p67

Okumus, F. (2001).Towards a strategy implementation framework. Int. J. Contemp. Hosp. Manage., 13: 327-338.

Olum, Y. (2004). Modern management theories and practices. Uganda: Makerere University.

Pirayeh, N., Mahdari, A. M., \& Nematpour, A. M. (2011). Study of organizational culture influence (Based on Dennison's Model) on effectiveness of human resources in Karun Oil \& Gas Production Company. Australian Journal of Basic and Applied Sciences, 5(9), 1886-1895.

Schaap, J. I. (2006). Toward strategy implementation success: An empirical study of the role of senior-level leaders in the Nevada gaming industry. Res. Rev. J. 10:13-37.

Rajasekar, J. (2014). Factors affecting Effective Strategy Implementation in a Service Industry: A Study of Electricity Distribution Companies in the Sultanate of Oman. International Journal of Business and Social Science, 5(9),

Quinn, R., Faerman, S., Thompson, M., McGrath, M., \& Clair, L. (2007). The competing values approach to management. In Quinn, et al., Becoming a master manager: A competing values approach (1-34). Hoboken NJ: John Wiley \& Sons, Inc.

Rick, T. (2013). What is the relationship between corporate culture and strategy? Retrieved from https://www.torbenrick.eu/blog/strategy/relationship-between-culture-and-strategy/

Ruona, W. E. A., \& Gibson, S. K. (2004). Maximizing the strategic contribution of people in organizations: An analysis of the convergence of HRM, HRD and OD. In T. S. Rocco \& G. D. Ludwig (Eds). Human resource management 43(1), 4966.

Santiago, P. Trenblay, K., Basri, E. \& Arnal, E. (2008). Internationalisation: Shaping strategies in the national context. Tertiary education for the knowledge society, 2 (235-309), Paris: OECD.

Sanz-Valle, R., Naranjo-Valencia, J.C., Jimenez-Jimenez, D. \& Perez-Caballero, L. (2011). Linking organizational learning with technical innovation and organizational culture. Journal of Knowledge Management, 15(6), 997-1015. https://doi.org/10.1108/13673271111179334

Sarstedt, M. \& Mooi, E. (2014). The process, data, and methods using IBM SPSS Statistics. A Concise Guide to Market Research. Springer: Berlin.

Sazali, A. W., Hashinda, A., Jegak, U. \& Raduan, C. R. (2010). Age of joint venture, inter-firm technology transfer and local firms' performance. Asian Social Science, Vol.6 (2). Doi:10.5539/ass.v6n2p28

Schein, E. H. (2009b). The corporate culture survival guides (2nd ed.). San Francisco: Jossey-Bass.

Sekulić, V. (2002). The importance of corporate strategic processes in managing efficiency of enterprise. Economics and Organization 1(10), $67-74$.

Sensusea, D. I., Cahyaningsiha, E. \& Wibowoa (2015). Knowledge management: Organizational culture in Indonesian government human capital management. Procedia Computer Science, 72 (2015) 485 - 494.

Sevilla, C. G., Ochave, J. A., Punsalan, T. G., Regala, B. P. \& Uriarte, G. G. (2007). Research Methods (Revised ed.). Quezon City, Philippine: Rex Printing Company, Inc.

Smart, J. C. \& John, E. P. (1996). Organizational culture and effectiveness in higher education: test of the 'culture type' and 'strong culture' hypothesis. Educational Evaluation and Policy Analysis, 18(3), $219-241$. https://doi.org/10.3102\%2F01623737018003219

Soni, R. G., Chaubey, M. D. \& Ryan, J. C. (2000). Implementing TQM in higher education institutions: A strategic approach. Academy of Educational Leadership Journal, 4(1), 2000.

Swanson, R. A., \& Holton, E. F. (2009). Foundations of human resource development (2nd ed.). San Francisco: Berrett-Koehler Publishers.

Tierney, W. G. (2008). The impact of culture on organizational decision-making: Theory and practice in higher education. Sterling, VA: Sylus Publishing, LLC.

$\mathrm{Yu}, \mathrm{T} . \& \mathrm{Wu}, \mathrm{N}$. (2009). A review of study on the Competing Values Framework. International Journal of Business and Management, 4(7), 2009. Doi:0.5539/ijbm.v4n7p37. 